\title{
Analyzing the Relationship between the Students' Stress-Coping Styles and School Attachment
}

\author{
Neslin İhtiyaroğlu ${ }_{\star} \bowtie$ \\ Öznur Tulunay Ateş ${ }^{2}$ \\ ${ }^{I}$ Krrlkkale Univesity, Faculty of Education, Yahsihan, Krrlkkale, Turkey \\ Email:neslin52@gmail.com \\ ${ }^{2}$ Mehmet Akif Ersoy University, Faculty of Education, Burdur, Turkey
}

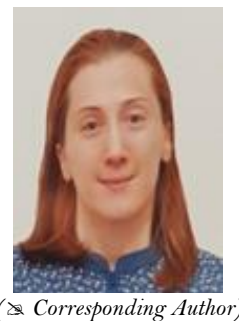

\begin{abstract}
Stress is an integral part of daily life for students like all adults. For this reason, one of the important functions of education is to enable students to learn healthy ways of stress coping. Besides, school attachment, which affects students' behavioral, psychological and social development, is also influenced by many variables such as stress level. However, in the related literature, the relationship between students' stress-coping styles and students' school attachment has not been fully elucidated. In this context, this study examines the predictive role of students' stress-coping styles on school attachment. The relational research model was used in the study. Five hundred and eighty-seven high school students selected by simple random sampling in Ankara province were administered Coping Styles Inventory and Scale for School Engagement. Using social support differs by sex and school attachment differs by class level. There is a positive relationship between seeking of social support, self-confident approach, optimistic approach and school attachment; a negative relationship between helpless approach and submissive approach and school attachment. Self-confident approach, submissive approach, and seeking of social support are were significant predictors of school attachment. Recommendations as regards increasing the level of student attachment presented in the end of the study.
\end{abstract}

Keywords: Student, Stress, Stress-coping styles, School attachment.

Citation | Neslin İhtiyaroğlu; Öznur Tulunay Ateş (2018). Analyzing the Relationship between the Students' Stress-Coping Styles and School Attachment. Asian Journal of Education and Training, 4(4): 371-379.

\section{History:}

Received: 14 June 2018

Revised: 21 August 2018

Accepted: 25 September 2018

Published: 19 October 2018

Licensed: This work is licensed under a Creative Commons

Attribution 3.0 License (cc)

Publisher:Asian Online Journal Publishing Group
Contribution/Acknowledgement: Both authors contributed to the conception and design of the study.

Funding: This study received no specific financial support

Competing Interests: The authors declare that they have no conflict of interests.

Transparency: The authors confirm that the manuscript is an honest, Transparency: The authors confirm that the manuscript is an honest,
accurate, and transparent account of the study was reported; that no vital features of the study have been omitted; and that any discrepancies from the study as planned have been explained.

Ethical: This study follows all ethical practices during writing.

\section{Contents}

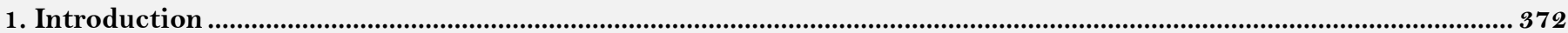

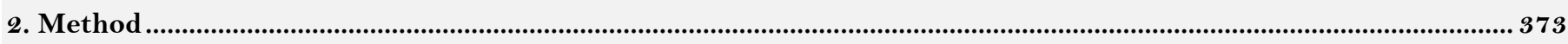

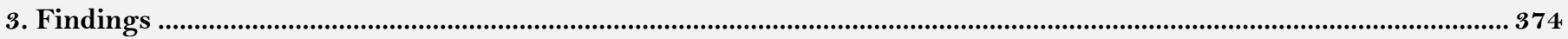

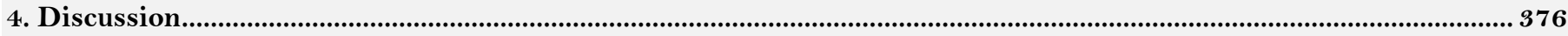

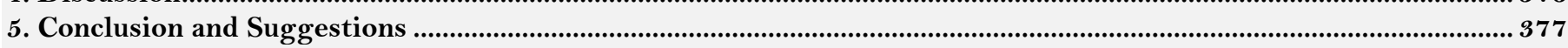

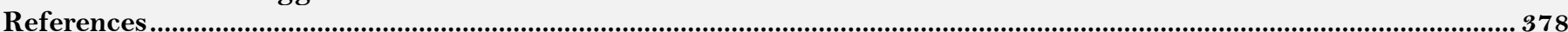




\section{Introduction}

High-level stress is one of the significant factors that adversely affect the effectiveness and efficiency of individuals, induce physiological, psychological and behavioral problems and make individuals unhappy. Occurring as a result of the individuals' interaction with the environment, said factor has become an integral part of both the daily life, and today's business life.

Even though stress is a factor that may exist anytime throughout life, it is difficult to provide a simple definition due to the various factors that stress affects or is being affected. Therefore, the definition of stress varies. Stress can be defined as physical and psychological instabilities occurring inside the internal world of the individual originated from environmental, organizational, or personal factors (Can et al., 2015) efforts shown by the individual above one's capacity due to the incompatibility of physiological and sociological conditions (Cüceloglu, 2009) phenomenon that occurs, when the individual fails to cope with the factors that emerge as a result of interaction with the environment (Lazarus and Folkman, 1984) and the state of psychological stimulation that emerges, when the external demands exceed the individual's ability to adapt (Lazarus, 1966).

Stress is an integral part of the daily life of the students as it is that of all the adults (Smith, 1993). Stress affecting the students may arise from academic, financial, time, and relation factors or it may be originated in the individual oneself (Dusselier et al., 2005). Moreover, the personal and emotional traits of the students, the physical structure of the school, environmental reasons, the behaviors of school administrator and teacher, and familial reasons are among the sources of stress in the students (Ardic, 2009).

Relevant studies suggested the level of stress as experienced by the students, the sources of stress, and its outcomes. Akande et al. (2014) found that the stress levels of the secondary school students were medium and associated with academic, environmental, or personal sources. Furthermore, the level of stress varied by sex, and stress level of girl students was found to be higher than boys'. Leonard et al. (2015) determined that the high school students were exposed to high level stress since they had to be academically successful to be accepted to top tier universities. Misra and McKean (2000) stated that the university students experienced high-level stress due to academic pressure and the fact that they could not find sufficient time to work together, get rest, and make use of their spare time, which caused anxiety, inquietude, tenseness, and sometimes depression. The results of a study by the American Psychology Association (APA) on 1200 young individuals aging between 8 and 17 years revealed that forty-two percentages of the young individuals failed to do their best to manage stress or were not sure if they did so. Thirty-seven percentages of girls and twenty-three percentages of boys felt unhappy and depressive due to stress, thirty-five percentage experienced insomnia on the nights they had to go to school the other day, thirty-

Stress-coping process can also be taken as problem-focused coping and emotion focused coping (Lazarus, 1966). In the problem-focused coping process, the individual is focused on solving the problems and changing the sources of stress; whereas in emotion focused coping the individual is focused on mitigating and managing the emotional distress as a result of stress (Carver et al., 1989). The individual resorts to the problem focused coping strategies, when one considers that a resolving process as regards the source of stress can be developed, and uses the emotionfocused coping strategies when one considers that the source of stress has to be tolerated (Folkman and Lazarus, 1980). In other words, the problem-focused coping means that the individual actively demonstrates behaviors related to the solution of the problems three percentage overate or resorted to unhealthy nutrition, and sixty-seven percentages skipped a meal due to lack of appetite as a result of stress (American Psychological Association, 2009).

Three reactions or outcomes may occur in the individuals due to stress: An individual may act neutral against the sources of stress, when he or she encountered with such sources; may effectively manage stress in order to protect one's physiological and psychological health; fail to manage stress and may experience physiological and psychological disorders and even fatal outcomes (Antonovsky, 1987). Raising the students as healthy individuals in physiological and psychological terms is only possible by ensuring that they effectively manage the stress. Therefore, one of the important functions of education is to ensure that the students learn healthy ways of coping with stress (Rohrkemper and Corno, 1988).

Stress can be healthily managed upon effective use of coping strategies (Kreitner and Kinicki, 1989). Coping strategies are the psychological and physiological efforts shown by the individual against a situation that leads to stress with an aim to control the situation, tolerate the situation, and mitigate or minimize the effects of the situation (Watson et al., 2008). An individual that faces to a situation that creates stress tends to use active or passive coping strategies alternately. The active coping strategies stand for the individual's active management of such processes as thinking, accepting, planning, and positively arranging in order to eliminate the stress factor, where the passive coping strategies refer to avoidance of coming across a situation that creates stress through such processes as denial, behavioral dissociation, substance or alcohol use, or mockery (Carver, 1997).

through a process of decision-making and active action where emotion-focused coping means that the individual thinks that the problem cannot be solved (Folkman, 1984). Sahin and Durak (1995) investigated the stress coping process based on the problem-focused and emotion-focused coping strategies under five different approaches of self-confident approach, optimistic approach, helpless approach, submissive approach, and seeking of social support. The self-confident approach denotes active and conscious endeavor of the individual towards the solution of the situation that creates stress; the optimistic approach denotes assessment of the situation that creates stress in the framework of positive perspective, tolerance, and logic; the helpless approach denotes the individual's loss of confidence towards the solution of the situation that creates stress and fail; the submissive approach denotes the fact that the individual seeks the solution at supernatural powers by a fatalist attitude since he or she feels week; and seeking of social support denotes seeking help from the individuals from the social environment towards the solution of the situation that creates stress.

Studies on the stress-coping styles of the students have determined the stress-coping strategies used by the students and the factors affect and being affected by such strategies. Relevant studies suggested that compared to the male students, the female students more frequently used emotional coping (Brougham et al., 2009) and imagination strategies (Demircioglu, 2014). Esia-Donkoh et al. (2011) found that the students more frequently used the emotion-focused coping strategies compared to the problem-focused coping strategies. Kumar and Bhukar (2013) demonstrated that the students stress-coping styles varied by sex, and that males resorted to the stress- 
coping strategies more frequently than the females in occupational issues. Deniz (2006) concluded that there was a positive relationship between students' life satisfaction and problem-focused coping styles and between stress coping styles, decision making ways, and self-respect. According to Durmus and Tezer (2001) students with higher sense of humor used the optimistic and self-confident coping styles more frequently. Ekinci et al. (2013) suggested that the assertiveness levels of the students increased as the stress- coping levels increased. On the other hand, Leonard et al. (2015) found that combined with the high expectations of the families, the intensive academic curriculum may pave the way for students using substance to cope with stress.

A review of the above-mentioned studies suggests that the stress-coping strategies are closely associated with many variables that affect students. School attachment is one of the variables with high impact on the academic, behavioral, and psychological status of the students. The school attachment level is considered important due to the fact that higher levels provide students with academic, behavioral, and psychological contribution and that lower levels cause adverse experiences in students in academic, behavioral, and psychological terms.

The school attachment can be defined differently due to the fact that it is affected by different variables. Moody and Bearman (1998) defined the school attachment as the degree to which students are close to the other individuals at school, enjoying being at school, and feeling themselves a part of the school. Goodenow (1993) considered the school attachment as school membership based on Wehlage's social membership theory and investigated the teacher-student relations and the levels the students attach importance to the thoughts of other individuals at school, and the levels they meet their expectations. The school attachment can be defined as the bond the students establish through their relations with the teachers, administrators, peers, social activities, and the sense of belonging that they develop thanks to said bond.

Jimerson et al. (2003) "the situation in which students adopt the objectives of the school and feel themselves a part of the school" (Finn, 1993) as cited in, Arastaman (2009).

The school attachment is studied under three dimensions of behavioral, cognitive, and affective. The behavioral attachment denotes the students' observable behaviors such as complying with the rules, remaining committed to classroom norms, attendance, attention, asking questions, participating in classroom discussions, and participating in social and sportive. Cognitive attachment is associated with the level of flexibility of the students in problem solving, level of preferring challenging tasks, and effectively overcoming the failure situation. Students with higher level of cognitive attachment are focused on fulfilling their responsibilities, achieving top-tier tasks, and investing in the learning process. The affective attachment denotes the emotional reactions of the students towards the school and individuals at school. The attitude of students towards their teachers, administrators, and peers, and their level of happiness at school are covered in the scope of affective attachment (Fredricks et al., 2004). In the scope of the present study, the school attachment in discussion is the affective attachment. It is thought the most important one because of the power of emotions acting individuals and directing behaviors (Goleman, 2009).

Relevant studies revealed many variables that affect the school attachment level and are affected by the school attachment level. Cemalcilar (2010) found that the satisfaction from the student -friend, teacher and administrator relations had a positive effect on student's school attachment. Mouton et al. (1996) showed in their study that the students with lower school attachment levels felt lonely and isolated at school. Those students had a prevalent perception that they were alienated and did not receive support and encouragement from their peers and school employees. Furthermore positive associations have been found between the school attachment level and academic success (Goodenow and Grady, 1993; Bond et al., 2007) self-efficacy and being target-oriented (Caraway et al., 2003) social support behaviors of teachers (Brewster and Bowen, 2004) teacher-parent communication (Murray, 2009) whereas negative associations have been found between the school attachment level and drop out level (Archambault et al., 2009) fear of failure (Caraway et al., 2003) and attitudes towards violence (Balkis et al., 2005).

All the aforementioned studies showed that the high levels of school attachment provided students with positive contribution in academic, social, and psychological terms. Having been quite important for the students, this variable may be affected by the ways the students cope with stress, which is an integral part of their daily lives. Determining the predictive role of the students' stress-coping styles on the school attachment may help with the process by which the school attachment levels of students is improved. Students having high level of school attachment may be academically, socially and psychologically more effective. Also, studies on predictive role of students' stress-coping styles on the school attachment are very limited both in the international and national literature and there is a gap on this topic. This study is thought important because of both finding out the predictive factors on school attachment and filling the gap in the literature. In that context, the present research aims to find the relation between the students' stress-coping styles and school attachment. Answers to below questions were sought to achieve the said purpose:

i. What are the students' stress-coping styles?

ii. What are the students' school attachment levels?

iii. Is there a significant difference in students' stress-coping styles and school attachment by sex and class level?

iv. Is there a significant relation between the students' stress-coping styles and school attachment?

v. Does the students' stress-coping styles (self-confident approach, optimistic approach, helpless approach, submissive approach and seeking of social support) predict their school attachment?

\section{Method}

\subsection{Research Model}

The relational survey model, which aims to determine the existence or degree of covariance between two or more variables (Karasar, 2006) was used in the present research that aimed to find the predictive level of students' stress-coping styles on school attachment.

\subsection{Population and Sample}

The population of the present research is composed of 127,206 students attending to secondary education institutions in 5 districts (Altındağ, Çankaya, Etimesgut, Sincan, and Yenimahalle) of Ankara in Turkey province 
according to the 2016-2017 Educational Year data. The sample is composed of 587 students, who were reached from the secondary schools in such districts by convenience sampling method. The demographic properties of the students involved in the sample are provided in Table 1:

Table-1. The demographic properties of the students involved in the sample $(\mathrm{n}=587)$

\begin{tabular}{l|l|c|c}
\hline \multicolumn{2}{l}{ Variables } & $\boldsymbol{n}$ & $\mathbf{\%}$ \\
\hline \multirow{2}{*}{ Sex } & Female & 329 & 56 \\
\cline { 2 - 4 } & Male & 258 & 44 \\
\hline \multirow{3}{*}{ Class } & $9^{\text {th }}$ Class & 161 & 28 \\
\cline { 2 - 4 } & $10^{\text {th }}$ Class & 137 & 23 \\
\cline { 2 - 4 } & $11^{\text {th }}$ Class & 149 & 24 \\
\cline { 2 - 4 } & $12^{\text {th }}$ Class & 140 & 24 \\
\hline
\end{tabular}

\subsection{Data Collection Tools}

Two measurement tools were used for the purpose of collecting data required for the research: Coping Styles Scale developed by Sahin and Durak (1995) and the School Attachment Scale developed by Iyaroglu (2014) based on the affective dimension items of the School Engagement Scale developed by Arastaman (2009).

Coping Styles Scale: The Coping Styles Scale is composed of five dimensions: self-confident approach (7 items), optimistic approach (5 items), helpless approach (8 items), submissive approach (6 items), and seeking of social support (4 items). The scale is total of 30 items. Item 9 was reverse coded on the grounds that it contained a negative meaning this four-point Likert type scale, which is rated between o (\%o) - 3 (\%100). The internal consistency coefficients of the Coping Styles Scale, which has been used widespread by many studies (Temel $e t$ al., 2007; Kelleci et al., 2012; Capulcuoglu and Gunduz, 2013) vary between .45 and .80 (Sahin and Durak, 1995). According to the results of confirmatory factor analysis which was conducted in order to determine the construct validity of the scale, $\mathrm{RMSEA}=.008, \mathrm{CFI}=.92$, and GFI $=.94$. These findings suggest the scale can be well explained under five subdomains. Moreover, the internal consistency coefficients as calculated for the domains of the scale were as follows: self-confident approach, .76; optimistic approach, .71; helpless approach, .67; submissive approach, .69; and seeking of social support, .69.

School Attachment Scale: The one-dimension School Attachment scale is a five-point Likert type scale rated between 1 (I don't agree at all) and 5 (I completely agree). The scale is total of 27 items. The analyses in this study showed that the Cronbach's alpha value was .89 and that the adjusted item-total correlation coefficients varied between .32 and .62. According to the Exploratory Factor Analysis, the factor loading values of its items varied between .34 and .72 and that the explained total variance was approximately $42 \%$. According to the results of confirmatory factor analysis which was conducted in order to determine the construct validity of the scale, RMSEA $=.006$, CFI $=.90$, and GFI $=.90$. These findings suggest the scale can be well explained under one subdomain.

\subsection{Data Collection}

Data in this study was collected based on volunteerism. The scale was administered after the permission was taken from course teachers. The students were given information about the purpose of the study before the scale administrated. It took approximately 15 minutes to collect the data in a class.

\subsection{Analysis of Data}

The data collected by the scales were tested by the t-test, a parametric test, one-way analysis of variance (ANOVA), correlation and multiple regression analyses using the SPSS 20 software package. The association between the stress-coping styles and school attachment by sex was determined by the t-test and the association between the stress-coping styles and school attachment by class level was determined by one-way analysis of variance. The correlation analysis revealed the degree and direction of the relation between the students' stresscoping styles and school attachment, where the multiple regression analysis, made with enter method in which independent variables are entered and evaluated in one step, suggested the predictive role of the students' stresscoping styles on school attachment.

\section{Findings}

The findings of the study are presented in this section under the subtitles parallel to the research questions. The first part includes the mean and standard deviation values for the students' stress-coping styles and school attachment followed by the findings as regards the relation between the students' stress-coping styles and school attachment with sex and class level. The second part provides the findings as regards the relations between the students' stress-coping styles and school attachment and the findings as regards the predictive role of the students' stress-coping styles on school attachment.

\subsection{Mean and Standard Deviation Values of the Variables and Findings as Regards the Relation of the Variables with the Sex and Class Level Factors}

Table 2 provides the mean and standard deviation values of the variables.

A review of Table 2 suggests that the variable with the highest mean value is the school attachment. Seeking of social support $(\bar{x}=2.47)$ and self-confident approach $(\bar{x}=2.22)$ has the highest mean values within the stresscoping styles. Variables with the least mean values are submissive approach $(\bar{x}=.68)$ and helpless approach $(\bar{x}=$ .89). 
Table-2. The mean and standard deviation values of the variables

\begin{tabular}{l|c|c|c}
\hline Variables & $\boldsymbol{n}$ & $\overline{\mathrm{X}}$ & $\boldsymbol{S}$ \\
\hline Self-Confident Approach & 587 & 2.22 & 1.22 \\
\hline Optimistic Approach & 587 & 2.07 & 1.54 \\
\hline Helpless Approach & 587 & 0.89 & 2.24 \\
\hline Submissive Approach & 587 & 0.68 & 1.32 \\
\hline Seeking of Soc. Support & 587 & 2.47 & 2.32 \\
\hline School Attachment & 587 & 3.45 & 0.97 \\
\hline Source: Calculated from primary data & &
\end{tabular}

Source: Calculated from primary data

Table 3 provides the mean and standard deviation values for the students' stress-coping styles and school attachment by sex and the t-test results indicating the relation of those variables with sex:

\begin{tabular}{|c|c|c|c|c|c|c|}
\hline Variables & Sex & $n$ & $\overline{\bar{X}}$ & $\boldsymbol{S}$ & $t$ & $p$ \\
\hline \multirow{2}{*}{ Self-Confident Approach } & Female & 329 & 2.20 & 1.23 & \multirow[t]{2}{*}{1.54} & \multirow[t]{2}{*}{.47} \\
\hline & Male & 258 & 2.26 & 1.23 & & \\
\hline \multirow{2}{*}{ Optimistic Approach } & Female & 329 & 2.14 & 1.38 & \multirow[t]{2}{*}{2.31} & \multirow[t]{2}{*}{.36} \\
\hline & Male & 258 & 1.99 & 1.37 & & \\
\hline \multirow{2}{*}{ Helpless Approach } & Female & 329 & 0.63 & 1.89 & \multirow[t]{2}{*}{-0.97} & \multirow[t]{2}{*}{.63} \\
\hline & Male & 258 & 0.69 & 1.89 & & \\
\hline \multirow{2}{*}{ Submissive Approach } & Female & 329 & 0.65 & 1.35 & \multirow[t]{2}{*}{-1.11} & \multirow[t]{2}{*}{.16} \\
\hline & Male & 258 & 0.71 & 1.32 & & \\
\hline \multirow{2}{*}{ Seeking of Social Support } & Female & 329 & 2.65 & 1.47 & \multirow[t]{2}{*}{2.17} & \multirow[t]{2}{*}{$.00^{*}$} \\
\hline & Male & 258 & 2.27 & 1.45 & & \\
\hline \multirow{2}{*}{ School Attachment } & Female & 329 & 3.31 & 0.87 & \multirow[t]{2}{*}{1.76} & \multirow[t]{2}{*}{.54} \\
\hline & Male & 258 & 3.59 & 0.84 & & \\
\hline
\end{tabular}

A review of Table 3 provides as regards the sex factor that optimistic approach $(\bar{X}=2.14)$, submissive approach $(\bar{X}=0.71)$, and seeking of social support $(\bar{X}=2.65)$ mean values of the girl students were higher than that of the boy students and that the self-confident approach $(\bar{X}=2.26)$, helpless approach $(\bar{X}=0.69)$, and school attachment $(\bar{X}=3.59)$ mean values of the boy students were higher than that of the girl students. The selfconfident approach, optimistic approach, submissive approach, and school attachment levels of the students did not have a significant difference by sex $(p>.05)$. On the contrary, the seeking of social support levels of the students had a significant difference by sex $(p<.05)$. The seeking of social support level $(\bar{X}=2.65)$ of females was higher than the seeking of social support level $(\overline{\mathrm{X}}=2.27)$ of males $[\mathrm{t}(2343,78)=2.17, p .<.001]$.

Table 4 provides the ANOVA results indicating the relation of the students' stress-coping styles and school attachment with the class level:

Table-4. The ANOVA results indicating the relations of variables with class level $(n=587)$

\begin{tabular}{|c|c|c|c|c|c|c|c|c|c|c|c|}
\hline \multirow[t]{2}{*}{ Variables } & \multicolumn{2}{|c|}{$\begin{array}{l}9^{\text {th }} \text { Class } \\
(161)\end{array}$} & \multicolumn{2}{|c|}{$10^{\text {th }} \operatorname{Class}(137)$} & \multicolumn{2}{|c|}{$\begin{array}{l}11^{\text {th }} \\
\text { Class }(149)\end{array}$} & \multicolumn{2}{|c|}{$12^{\text {th }} \operatorname{Class}(140)$} & \multirow{2}{*}{$\boldsymbol{F}$} & \multirow{2}{*}{$p$} & \multirow{2}{*}{$\begin{array}{l}\text { Scheffe } \\
\text { test }\end{array}$} \\
\hline & $\bar{x}$ & $S$ & $\bar{X}$ & $\boldsymbol{S}$ & $\bar{x}$ & $S$ & $\bar{X}$ & $S$ & & & \\
\hline Self-Confident Approach & 1.98 & .22 & 2.17 & 1.23 & 2.36 & .21 & 2.28 & 1.23 & .56 & .27 & \\
\hline Optimistic Approach & 2.02 & .56 & 1.97 & 1.52 & 2.17 & 1.54 & 2.07 & 1.54 & .96 & .12 & \\
\hline Helpless Approach & 0.79 & .21 & 0.99 & 2.21 & 1.01 & 2.22 & 0.74 & 2.20 & .87 & .65 & \\
\hline Submissive Approach & 0.74 & .32 & 0.61 & 1.29 & 0.66 & 1.36 & 0.69 & 1.29 & .68 & .86 & \\
\hline Seeking of Social Support & 2.45 & .26 & 2.49 & 2.29 & 2.51 & 2.29 & 2.47 & 2.31 & .98 & .48 & \\
\hline School Attachment & 3.25 & .01 & 3.47 & 0.89 & 3.51 & 0.91 & 3.59 & 1.02 & .21 & $.01^{*}$ & $1-3,1-4$ \\
\hline
\end{tabular}

1: $9^{\text {th }}$ Class; 2: $10^{\text {th }}$ Class; $3: 11^{\text {th }}$ Class; 4: $12^{\text {th }}$ Class

Source: Calculated from primary data *Level of significance at $\mathrm{p}<.05$

A review of Table 4 provides that the mean values of seeking of social support and self-confident approach, as the most frequently used stress-coping styles of the students, increased as the class level increased, yet there was a decline in the mean values of both variables at $12^{\text {th }}$ class. It was seen that the students' stress-coping styles, i.e. selfconfident approach, optimistic approach, helpless approach, submissive approach, and seeking of social support subdomains did not differ by class level $(p>.05)$. On the other hand, the school attachment of the students differed by class level $(p<.05)$. According to the results of the Scheffe test, the said difference regarding the school attachment occurred in $9^{\text {th }}$ class compared to the $11^{\text {th }}$ class and $12^{\text {th }}$ class. The school attachment levels of the $11^{\text {th }}$ class students $(\bar{X}=3.51)$ and $12^{\text {th }}$ class students $(\bar{X}=3.59)$ were higher than the school attachment levels of the $9^{\text {th }}$ class students $(\bar{X}=3.25)$.

\subsection{Findings As Regards the Predictive Role of the Students' Stress-Coping Styles on School} Attachment

The findings as a result of the correlation analysis aimed to determine the relations between the students' stress-coping styles and school attachment are presented in Table 5: 
Table-5. Relations between variables

\begin{tabular}{l|l|l|l|l|l|l|l}
\hline Variables & $\mathbf{1}$ & $\mathbf{2}$ & $\mathbf{3}$ & $\mathbf{4}$ & $\mathbf{5}$ & $\mathbf{6}$ & $\mathbf{7}$ \\
\hline 1. Self-Confident Approach & 1 & & & & & & \\
\hline 2. Optimistic Approach & $.39^{* *}$ & 1 & & & & & \\
\hline 3. Helpless Approach & $-.27^{* *}$ & $-18^{*}$ & 1 & & & & \\
\hline 4. Submissive Approach & $-.13^{*}$ & $-.19^{*}$ & $.38^{* *}$ & 1 & & & \\
\hline 5. Seeking of Soc. Support & $.46^{* *}$ & $.39^{* *}$ & $-41^{* *}$ & $-.33^{* *}$ & 1 & & \\
\hline 6. School Attachment & $.41^{* *}$ & $.23^{* *}$ & $-.37^{* *}$ & $-.31^{* *}$ & $.48^{* *}$ & 1 & \\
\hline 7. Stress-coping Total & & & & & & $.42^{* *}$ & 1 \\
\hline ** $\mathrm{p}<.01 * \mathrm{p}<.05$ & & & &
\end{tabular}

Table 5 suggests that the highest relation with the school attachment was seen in seeking of social support $(\mathrm{r}=$ $.48, p<.01)$ and self-confident approach $(\mathrm{r}=.41, p<.01)$ variables. Furthermore, there was a positive significant relation between the school attachment and optimistic approach $(\mathrm{r}=.23, \mathrm{p}<.01)$ and a negative significant relation between the school attachment and the helpless approach $(\mathrm{r}=-.37, p<.01)$ and submissive approach $(\mathrm{r}=-.31, \mathrm{p}<$ $.05)$. On the other hand, there was a positive relation between the seeking of social support and self-confident approach $(\mathrm{r}=.41, p<.01)$ and optimistic approach $(\mathrm{r}=.39, p<.01)$; and there was a negative relation between the seeking of social support and helpless approach $(\mathrm{r}=-.41, p<.01)$ and submissive approach $(\mathrm{r}=-.33, p<.01)$. Besides, it was found positive relation between stress-coping total and school attachment $(\mathrm{r}=.42, p<.01)$.

The multiple regression results as regards the predictive role of self-confident approach, optimistic approach, helpless approach, submissive approach, and seeking of social support on school attachment are provided in Table 6 in line with the research sub-question of "Are Does the students' each stress-coping style predict school attachment?"

Table-6. Results of multiple regression analysis

\begin{tabular}{l|l|l|l|l|l}
\hline Variables & $\boldsymbol{B}$ & $\boldsymbol{S E}$ & $\boldsymbol{\beta}$ & $\boldsymbol{t}$ & $\boldsymbol{p}$ \\
\hline Constant & 54.24 & 9.43 & & 6.36 & .00 \\
\hline Self-Confident Approach & 1.27 & 1.56 & .48 & 1.67 & .00 \\
\hline Optimistic Approach & 1.12 & 1.51 & .37 & 4.32 & .48 \\
\hline Helpless Approach & -.89 & .12 & -.41 & -3.76 & .89 \\
\hline Submissive Approach & -.72 & .17 & -.23 & -3.87 & .00 \\
\hline Seeking of Social Support & 2.13 & 481 & .5 & 5.34 & .00 \\
\hline $\mathrm{R}=.53 \mathrm{R}^{2}=.48$ & & & &
\end{tabular}

A review of Table 6 provides that the self-confident approach, optimistic approach, helpless approach, submissive approach, and seeking of social support variables altogether render a high-level and significant relation with the school attachment $\left(\mathrm{R}=.53, \mathrm{R}^{2}=.48, \mathrm{p}<.01\right)$. The foregoing five variables altogether explained $48 \%$ of the total variance of school attachment. According to the standardized regression coefficient values $(\beta)$, the order of importance of the predictive variables on the school attachment was as follows: seeking of social support, selfconfident approach, helpless approach, optimistic approach, and submissive approach. A review of the t-test results regarding the significance of the regression coefficient values provides that the self-confident approach $(\beta=.48$, $\left.\mathrm{t}_{(167)}=1.67, \mathrm{p}<.01\right)$ and seeking of social support $\left(\beta=.57, \mathrm{t}_{(167)}=5.34, p<.01\right)$ predicted school attachment in a positive way and submissive approach $\left(\beta=-.23, \mathrm{t}_{(167)}=-3.87, p<.01\right)$ predicted school attachment in a negative way. The optimistic approach $\left(\beta=.37, \mathrm{t}_{(167)}=4.32, p>.05\right)$ and helpless approach $\left(\beta=-.41, \mathrm{t}_{(167)}=-3.76, p>.05\right)$ did not have a predictive role on the students' school attachment.

\section{Discussion}

The present study, which aimed to determine the predictive role of the students' stress-coping styles on school attachment, found that the school attachment level was the variable with the highest mean value among variables of the study and that the students most frequently used seeking of social support and self-confident approach in coping with a stressful situation. The fact that seeking of social support was the variable with the highest mean value may be associated with the fact that the students were in their adolescence period. The peer groups are rather important for the psychological and social development of the individuals during the adolescence period. The adolescents can more easily overcome the situations of crisis and chaos thanks to the individuals, who have the shared living place, same kind of problems, or responsibilities (Meric, 1999). Furthermore, based on the fact that the students cope with many physical, psychological, and social changes during the adolescence period (Akçan Parlaz et al., 2012) they may adopt a more belligerent perspective. Thanks to this perspective, they may use the self-confident approach that requires active and willing efforts towards eliminating the situation that creates the stress by means of that power of struggle. Çapık et al. (2017) found in their study that the students most frequently preferred seeking of social support and self-confident approach in coping with stress. On the other hand, it was seen that the students more frequently used healthy coping styles such as self-confident approach, optimistic approach, and seeking of social support compared to the unhealthy coping styles of the helpless and submissive approaches. The students' level of resorting to helpless approach and submissive approach in cases of a situation that creates stress was low. These results are coherent with the results of other relevant studies (Ekinci et al., 2013; Çapık et al., 2017). The high level of school attachment may be associated with a strong bond that the students established with the school due to the positive relations with teachers, administrators, and peers and participation in social activities, and feeling as a part of the school through the foregoing bond.

The present study found that the self-confident approach, optimistic approach, helpless approach, submissive approach of the stress-coping styles, and school attachment did not differ significantly by sex, whereas seeking of social support dimension significantly differed by sex. Namely, compared to males, females more frequently sought the assistance of their environment when they overcome a stressful situation. Ptacek et al. (1994) suggested in their 
study that females used emotion-focused coping styles more frequently and needed more social support compared to males. Moreover, other relevant studies (Amirkhan, 1990; Sahin and Durak, 1995; Așçı et al., 2015) confirmed that only seeking of social support approach of the stress-coping styles differed by sex and females used seeking social support more frequently than males. Furthermore, the result that the students' school attachment did not differ by sex was consistent with the results of the previous studies (Ihtiyaroglu and Demir, 2016). This may be because both males and females are in the same school environment and encounter the same situations.

Another result of this study is that the students use seeking of social support and self-confident approach more frequently when their class levels increase; yet there was a decline in the levels of use of seeking support and selfconfident approach at $12^{\text {th }}$ class. Besides, seeking social support and self-confident approach were lowest at $9^{\text {th }}$ class among the class levels. It may be associated with the fact that the $9^{\text {th }}$ class is the first year of the secondary education and that the students do not know each other well and have not socialized yet. Furthermore, a substantial part of the students at $9^{\text {th }}$ class belong to the first adolescence period involving 12-14 years old group. The changes in the said period are visible since they are quite fast (Cüceloglu, 2009). Many changes experienced in physical, cognitive, emotional, and social terms may adversely affect the students' level of interaction with their environment and their self-confidence. The levels of seeking social support and self-confident approach increased by the $10^{\text {th }}$ and $11^{\text {th }}$ classes upon realization of the meeting and socializing process by being at the end of the first adolescence period.

Nevertheless, the fact that there was a decline in the level of use of seeking social support and self-confidence approach in $12^{\text {th }}$ class may be explained by anxiety created by the higher education examination. Students in $12^{\text {th }}$ class may tend to move away social environment to prepare the examination and high level of anxiety may damage their self-confidence. Because of these reasons, the students' socialization and self-confidence levels may be adversely affected. However, the self-confident approach, optimistic approach, helpless approach, submissive approach, and seeking of social support did not differ significantly by the class level. This result suggests that the students' stress-coping styles are not associated with their class levels. Similarly, Hancioğlu (2017) found that the students' stress-coping styles did not differ by the class level. The results of both studies are consistent. On the other hand, the students' school attachment levels significantly differ by the class level.

The result indicating that the $11^{\text {th }}$ and $12^{\text {th }}$ class students had higher school attachment levels than $9^{\text {th }}$ class students may be explained by stronger bond with the school thanks to the longer time periods they spent at school. More time may help $11^{\text {th }}$ and $12^{\text {th }}$ students develop sincerer relations with the teachers, administrators, and peers and participate in more social activities.

The present study concluded that there was a positive relation between the stress coping styles of seeking of social support, self-confident approach, and optimistic approach and school attachment, where there was a negative relation between the helpless approach, submissive approach and the school attachment. Accordingly, as the levels of using seeking of social support, self-confident approach, and optimistic approach increased students' school attachment level; on the contrary, their school attachment levels decreased when they more frequently resorted to helpless approach and submissive approach. Furthermore, the relations among the self-confident approach, optimistic approach, and seeking of social support variables were positively significant. Besides, the helpless approach and submissive approach were positively significant, too. But the relations between the self-confident approach, optimistic approach and seeking of social support variables and the helpless approach and submissive approach were negatively significant.

Among the stress-coping styles, self-confident approach, submissive approach, and seeking of social support of the students' were each a significant precursor of the students' school attachment. On the contrary, the optimistic approach and helpless approach did not have a predictive role on the students' school attachment. In the light of the foregoing result, it can be argued that the affective school attachment would increase, when the students apply to self-confident approach and seeking of social support in case of a stressful situation, where their school attachment levels would decrease when they use submissive approach. Active and conscious endeavor of the individual or seeking help from the individuals from the social environment towards the solution of the situation that creates stress may help the effects of stress decrease and affective school attachment increase. On the other hand, the fact that the individual seeks the solution at supernatural powers by a fatalist attitude may cause students to leave control of their lives and not to cope with stress on their own. This process may damage their confidence toward people around and affect affective school attachment in a negative way. According to İhtiyaroğlu (2018) selfconfident approach, helpless approach, submissive approach, and seeking of social support are predictors of organizational commitment. Using self-confident approach and seeking of social support increase teachers' organizational commitment level whereas using helpless approach and submissive approach decrease their organizational commitment level when they face stressful situations. Results of these studies confirmed that selfconfident approach and seeking of social support affect the commitment positively and submissive approach affect the commitment negatively. The fact that helpless approach is not a predictor of school attachment may be explained by sampling of the study. Helpless approach, defined as individual's loss of confidence towards the solution of the situation that creates stress, may not suit bellicose point of view in adolescence. Furthermore, other relevant studies found significant relations between the students' stress coping styles and variables having affective features such as self-respect (Deniz and Yilmaz, 2006) the flexibility and confident attachment levels (Li, 2008) anger management (Arslan, 2010) attitudes as regards seeking psychological help (Türküm, 2001) and emotional intelligence (Deniz and Yilmaz, 2006). The results all the above studies and the present study confirm that there are significant relations between the students' stress coping styles and variables that affect students' affective features.

\section{Conclusion and Suggestions}

The present study, which aimed to determine the relation between the students' stress coping styles and levels of school attachment, found that the school attachment level was the variable with the highest mean value. The students most frequently use seeking of social support and self-confident approach when they encounter a situation that creates stress. On the other hand, the level the students use helpless approach and submissive approach, i.e. the 
unhealthy stress-coping styles, against a situation that creates stress is low. While the self-confident approach, optimistic approach, helpless approach, and submissive approach of the stress-coping styles and the school attachment do not significantly differ with by sex, the seeking of social support dimension significantly differs by sex. Furthermore, although the self-confident approach, optimistic approach, helpless approach, submissive approach, and seeking of social support dimensions do not significantly differ by class level, the students' school attachment levels shows a significant difference by class level. There are positive significant relations between the seeking of social support, self-confident approach, and optimistic approach of the students' stress-coping styles and the students' school attachment, where there are negative significant relations between the helpless approach and submissive approach and the students' school attachment. The self-confident approach, submissive approach, and seeking of social support of the students' stress-coping styles are each a significant precursor of the students' school attachment. On the contrary, the optimistic approach and helpless approach have no predictive power on the school attachment.

The students most frequently used seeking of social support and self-confident approach when they encounter stressful situations; there are positive significant relations between the foregoing variables and the students' school attachment and there are negative significant relations between helpless approach and the students' school attachment, such variables are predictors of the school attachment. In the light of these results, school and classroom environments, where the students show active and willful efforts and receive support towards solution from the individuals in the environment may contribute in the students' school attachment level. Primarily the school principal is responsible for the formation of the school climate and the teachers are responsible for the formation of the classroom climate.

A school environment in which administrators and teachers are easily accessible, the school and classroom rules and expectations are clearly expressed, there exists a positive communication among the peers, all the stakeholders actively take part in decision making process, innovation, development, and cultural pluralism are promoted, and the students feel safe, may contribute the students' use of social support and self-confident approach. Therefore, students' level of school attachment would increase. Furthermore, courses related to stress, an integral part of daily life and affective coping with stress may be added to curricula to help students raise awareness. Psychological counseling and guidance services of the schools may organize awareness seminars for the students on healthy stress coping styles. Further studies may investigate the culture and climate of the schools and classrooms, where the students adopt healthy and unhealthy styles of stress-coping, which would serve as a guide for the administrators and teachers, who aim to increase the students' school attachment.

\section{References}

Akande, J., A. Oloonirejuaro and C. Kalu, 2014. A study of level and sources of stress among secondary school students. IOSR Journal of Research and Method in Education, 4(5): 32-36.Available at: https://doi.org/10.9790/7388-04513236.

Akçan Parlaz, E., N. Tekgül, E. Karademirci and K. Öngel, 2012. Adolescence period: Physical growth, psychological and social development process. Turkish Family Physician, 3(4): 10-16.

American Psychological Association, 2009. Stress in America New York City Report. New York: Harris Interactive Inc. Retrieved from https://www.apa.org/news /press/releases/stress/2009/stress-new-york.pdf.

Amirkhan, J.H., 1990. A factor analytically derived measure of coping: The coping strategy indicator. Journal of Personality and Social Psychology, 59(5): 1066-1074.Available at: https://doi.org/10.1037//0022-35 14.59.5.1066.

Antonovsky, A., 1987. Unraveling the mystery of health: How people manage stress and stay well. San Francisco: Jossey-Bass.

Arastaman, G., 2009. The views of the students, teachers and administrators about the high school first year students' adherence to school. Pamukkale University Faculty of Education Journal, 26(1): 102-112.

Archambault, I., M. Janosz, J.-S. Fallu and L.S. Pagani, 2009. Student engagement and its relationship with early high school dropout. Journal of Adolescence, 32(3): 651-670.Available at: https://doi.org/10.1016/j.adolescence.2008.06.007.

Ardic, A., 2009. Stress factors and coping behaviors in students. Ankara: T. C. Ministry of National Education, Education Research and Development Department.

Arslan, C., 2010. Investigation of anger and anger expression in terms of coping with stress and interpersonal problem solving. Educational Sciences in Theory and Practice, 10(1): 7-43.

Aşçı, Ö., G. Hazar, E. Kılıç and A. Korkmaz, 2015. Determination of stress causes and coping forms in university students. Uşak University Journal of Social Sciences, 8(4): 213-231.

Balkis, M., E. Duru and M. Invention, 2005. Attitudes towards violence, self-efficacy, media, belief in violence, group of friends and a sense of commitment to school. Ege Education Journal, 2(6): 81-97.

Bond, L., H. Butler, L. Thomas, J. Carlin, S. Glover, G. Bowes and G. Patton, 2007. Social and school connectedness in early secondary school as predictors of late teenage substance use, mental health, and academic outcomes. Journal of Adolescent Health, 40(4): $357-$ 376.Available at: https://doi.org/10.1016/j.jadohealth.2006.10.013.

Brewster, A.B. and G.L. Bowen, 2004. Teacher support and the school engagement of latino middle and high school students at risk of school failure. Child and Adolescent Social Work Journal, 21(1): 47-67.Available at: https://doi.org/10.1023/b:casw.0000012348.83939.6b

Brougham, R.R., C.M. Zail, C.M. Mendoza and J.R. Miller, 2009. Stress, sex differences, and coping strategies among college students. Current Psychology, 28(2): 85-97.Available at: https://doi.org/10.1007/s 12 144-009-9047-0.

Can, H., O. Asan and E.M. Aydin, 2015. Organizational behavior. Ankara: Political.

Çapık, C., H. Durmaz and M. Öztürk, 2017. Nursing students' styles of coping with stress and affecting factors: Nicosia. Jour nal of Anatolian Nursing and Health Sciences, 20(3): 2018-2216.

Capulcuoglu, U. and B. Gunduz, 2013. Coping with stress, stress, academic competence and parental attitudes. Journal of Educational Sciences, 3(1): 201-218.Available at: https://doi.org/10.12973/jesr.2013.3111a.

Caraway, K., C.M. Tucker, W.M. Reinke and C. Hall, 2003. Self-efficacy, goal orientation, and fear of failure as predictors of school engagement in high school students. Psychology in the Schools, 4O(4): 417-427.Available at: https://doi.org/10.1002/pits.10092.

Carver, C.S., 1997. You want to measure coping but your protocol'too long: Consider the brief cope. International Journal of Behavioral Medicine, 4(1): 92-100.Available at: https://doi.org/10.1207/s15327558ijbm0401_6.

Carver, C.S., M.F. Scheier and J.K. Weintraub, 1989. Assessing coping strategies: A theoretically based approach. Journal of Personality and Social Psychology, 56(2): 267-283.Available at: https://doi.org/10.1037//0022-3514.56.2.267

Cemalcilar, Z., 2010. Schools as socialisation contexts: Understanding the impact of school climate factors on students' sense of school belonging. Applied Psychology, 59(2): 243-272.Available at: https://doi.org/10.1111/j.1464-0597.2009.00389.x.

Cüceloglu, D., 2009. Man and his behavior. 18th Edn., Ankara: Remzi.

Demircioglu, H., 2014. High school students' coping strategies. Journal of Academic Social Research, 2(7): 385-392.

Deniz, M., 2006. The relationships among coping with stress, life satisfaction, decision-making styles and decision self-esteem: An investigation with Turkish university students. Social Behavior and Personality: An International Journal, 34(9): 11611170.Available at: https://doi.org/10.2224/sbp.2006.34.9.1161. 
Deniz, M.E. and E. Yilmaz, 2006. The relationship between emotional intelligence and stress coping styles in university students. Turkish Journal of Psychological Counseling and Guidance, 3(25): 17-26.

Durmus, Y. and E. Tezer, 2001. The relationship between sense of humor and coping strategies. Turkish Psychology Journal, 16(47): 25-34.

Dusselier, L., B. Dunn, Y. Wang, M.C. Shelley iI and D.F. Whalen, 2005. Personal, health, academic, and environmental predictors of stress for residence hall students. Journal of American College Health, 54(1): 15-24.Available at: https://doi.org/10.3200/jach.54.1.15-24.

Ekinci, M., A.Ö. Şahin and G. Can, 2013. Examining the styles of coping with stress and the level of assertiveness in terms of some variables. Journal of Psychiatric Nursing, 4(2): 67-74.Available at: https://doi.org/10.5505/phd.2013.85856.

Esia-Donkoh, K., D. Yelkpieri and K. Esia-Donkoh, 2011. Coping with stress : Strategies adopted by students at the winneba campus of University of education. US-China Education Review, 1(2): 290-299.

Folkman, S., 1984. Personal control and stress and coping processes: A theoretical analysis. Journal of Personality and Social Psychology, 46(4): 839-852.Available at: https://doi.org/10.1037//0022-3514.46.4.839.

Folkman, S. and R.S. Lazarus, 1980. An analysis of coping in a middle-aged community sample. Journal of Health and Social Behavior, $21(3)$ : 219-239.Available at: https://doi.org/10.2307/2136617.

Fredricks, J.A., P.C. Blumenfeld and A.H. Paris, 2004. School engagement: Potential of the concept, state of the evidence. Review of Educational Research, 74(1): 59-109.Available at: https://doi.org/10.3102/00346543074001059.

Goleman, D., 2009. Emotional intelligence at work. Istanbul: Varlık Publications.

Goodenow, C., 1993. The psychological sense of school membership among adolescents: Scale development and educational correlates. Psychology in the Schools, 30(1): 79-90.Available at: https://doi.org/10.1002/1520-6807(199301)30:1<79::aidpits2310300 113>3.0.co;2-x.

Goodenow, C. and K.E. Grady, 1993. The relationship of school belonging and friends' values to academic motivation among urban adolescent students. The Journal of Experimental Education, 62(1): 60-71.Available at: https://doi.org/10.1080/00220973.1993.9943831.

Hancıoğlu, Y., 2017. Examining the relationship between perceived stress levels and stress coping styles of university students. Journal of Management and Economics Research, 15(1): 130-149.

İhtiyaroğlu, N., 2018. Analysis of relationship between teachers' coping styles with stress and the level of organizational commitment. International Online Journal of Educational Sciences, 10(2): 192-206.Available at: https://doi.org/10.15345/iojes.2018.02.013.

Ihtiyaroglu, N. and E. Demir, 2016. Examining school commitment levels of students with different locus of control. Black Sea Journal of Social Sciences, 7(3): 282-296.

Iyaroglu, N., 2014. Examining the relationship between school climate and teacher effectiveness. Unpublished Doctorate Dissertation, Gazi Üniversitesi Eğitim Bilimleri Enstitüsü, Ankara.

Jimerson, S.R., E. Campos and J.L. Greif, 2003. Toward an understanding of definitions and measures of school engagement and related terms. The California School Psychologist, 8(1): 7-27.Available at: https://doi.org/10.1007/bfo3340893.

Karasar, N., 2006. Scientific research methods. Ankara: Nobel.

Kelleci, M., Z. Golbasi, S. Inal and O. Kavakci, 2012. Non-smoker and non-smoker university students' coping styles with stress: Gender effect. Republican Journal of Medicine, 34(1): 9-16.Available at: https://doi.org/10.7 197/1305-0028.1052.

Kreitner, R. and A. Kinicki, 1989. Organizational behavior. Homewood, IL: Irwin.

Kumar, S. and J. Bhukar, 2013. Stress level and coping strategies of college students. Journal of Physical Education and Sport Management, 4(1): 5-11.

Lazarus, R.S., 1966. Psychological stress and the coping process. New York: McGraw-Hill.

Lazarus, R.S. and S. Folkman, 1984. Stress appraisal and coping. New York: Springer.

Leonard, N.R., M.V. Gwadz, A. Ritchie, J.L. Linick, C.M. Cleland, L. Elliott and M. Grethel, 2015. A multi-method exploratory study of stress, coping, and substance use among high school youth in private schools. Frontiers in Psychology, 6: 1028.Available at: https://doi.org/10.3389/fpsyg.2015.01028.

Li, M.-H., 2008. Relationships among stress coping, secure attachment, and the trait of resilience among Taiwanese college students. College Student Journal, 42(2): 312-326.

Meric, B., 1999. A review of some personality traits of young people popular within the group. Unpublished Master's Thesis. Marmara Üniversitesi, Sosyal Bilimler Enstitüsü, İstanbul.

Misra, R. and M. McKean, 2000. College students' academic stress and its relation to their anxiety, time management, and leis ure satisfaction. American Journal of Health Studies, 16(1): 41-51.

Moody, J. and P.S. Bearman, 1998. Shaping school climate: School context, adolescent social networks, and attachment to school. Unpublished Manuscript, Department of Sociology University of North Carolina, Chapel Hill.

Mouton, S.G., J. Hawkins, R.H. McPherson and J. Copley, 1996. School attachment: Perspectives of low-attached high school students. Educational Psychology, 16(3): 297-304.Available at: https://doi.org/10.1080/0144341960160306.

Murray, C., 2009. Parent and teacher relationships as predictors of school engagement and functioning among low-income urban youth. The Journal of Early Adolescence, 29(3): 376-404.Available at: https://doi.org/10.1177/027243 1608322940 \.

Ptacek, J.T., R.E. Smith and K.L. Dodge, 1994. Gender differences in coping with stress: When stressor and appraisals do not differ. Personality and Social Psychology Bulletin, 2O(4): 42 1-430.Available at: https://doi.org/10.1177/0146167294204009.

Rohrkemper, M. and L. Corno, 1988. Success and failure on classroom tasks: Adaptive learning and classroom teaching. The Elementary School Journal, 88(3): 297-3 12.Available at: https://doi.org/10.1086/461540.

Sahin, N. and A. Durak, 1995. Ways of coping with stress: Adaptation for university students. Turk J Psychol, 10(34): 56-73.

Smith, J.C., 1993. Understanding stress and coping. New York: McMillan.

Temel, E., A. Bahar and D. Çuhadar, 2007. Determining the levels of depression and nursing styles of student nurses. Firat Health Services Journal, 2(5): 107-118.

Türküm, S., 2001 . Relationships between stress attitudes, optimism, cognitive distortions and attitudes towards receiving psychological help: A study on university students. Anadolu University Journal of Social Sciences, 1(2): 1-16.

Watson, J.M., H.L. Logan and S.L. Tomar, 2008. The influence of active coping and perceived stress on health disparities in a multi-ethnic low income sample. BMC Public Health, 8(1): 41.Available at: https://doi.org/10.1 186/1471-2458-8-41. 